\title{
A multi-criteria stochastic programming approach for pre-positioning disaster relief supplies in Brazil
}

\author{
Irineu de Brito Junior, ${ }^{\mathrm{a}, \mathrm{b} *}$ (D), Adriana Leiras ${ }^{\mathrm{c}}$ (D), Hugo Tsugunobu Yoshida Yoshizaki ${ }^{\mathrm{b}}$ \\ aUniversidade Estadual Paulista, São José dos Campos, SP, Brasil \\ bUniversidade de São Paulo, São Paulo, SP, Brasil \\ 'Pontifícia Universidade Católica do Rio de Janeiro, Departamento de Engenharia Industrial, Rio de Janeiro, RJ, Brasil \\ *irineu.brito@unesp.br
}

\begin{abstract}
Paper aims: Considering that disaster preparedness is essential for a prompt and effective response, this paper presents a study to locate disaster relief supplies.

Originality: This paper marks the first time a multi-criteria stochastic methodology addresses humanitarian location problems.

Research method: We propose a multi methodology approach that employs an optimization model and a multi-criteria decision analysis. Based on logistics costs and penalties assigned for unmet demand, a stochastic model minimizes the total operational cost of opening distribution centers for pre-positioning disaster relief supplies. As decisions in humanitarian operations have multiple criteria and small differences in costs may not be significant by considering other criteria, we perform an analysis of the stochastic model solutions through Multi-criteria Decision Analysis.
\end{abstract}

Main findings: The findings show that the stochastics model leads to good results in uncertainty accommodation and that the consideration of qualitative and quantitative criteria improves decisions in humanitarian operations, especially when the supplies available are not enough to meet all the demand requirements.

Implications for theory and practice: The methodology was used by Civil Defense to locate warehouses for prepositioning relief supplies in Sao Paulo State, Brazil.

Keywords

Humanitarian logistics. Facility location. Stochastic optimization. MCDA. Multimethodology.

How to cite this article: Brito Junior, 1., Leiras, A., \& Yoshizaki, H. T. Y. (2020). A multi-criteria stochastic programming approach for pre-positioning disaster relief supplies in Brazil. Production, 30, e20200042. https://doi.org/10.1590/01036513.20200042 .

Received: Apr. 27, 2020; Accepted: June 15, 2020.

\section{Introduction}

Extreme weather events are likely to become more frequent as a result of climate change (Jeworrek, 2017). Climate change is also increasing the severity of these events, and disasters will continue to be major impediments to sustainable development (Wallemacq \& House, 2018).

The large number of victims and the unpredictable nature of such events make humanitarian operations a critical characteristic of disaster management and one of the main ways to improve the time, cost, and quality of relief operations (Blecken et al., 2009). Humanitarian logistics is a combination of preparedness and response (Tomasini \& Van Wassenhove, 2009). In the preparedness phase, the activities are a continuous process over the long term, without urgency, especially pre-positioning materials. The response phase is a fast supply process with a high level of urgency because the lead time for materials may jeopardize the rescue operation (Kessler, 
2013). The shortage of materials or inefficient management of resources could increase the suffering of the affected population.

Relief supplies are basic elements for affected people to have access to food and hygiene products at the first moments after the disaster. Agility and readiness in the distribution of these items are necessary, especially in the first 72 hours after the event (Salmerón \& Apte, 2010) so that rescue teams can begin the recovery activities, and the victims can thus stabilize their lives. Materials are also required for relief teams to act immediately after the event (response phase).

In the network configuration, the strategy for locating relief supplies along with the humanitarian supply chain is characteristically relevant to the response time for a disaster (Balcik \& Beamon, 2008). In preparedness phase, facility location decisions drive the performance of emergency relief operations in a disaster because the number and location of distribution centers directly affect the response time and costs incurred along the supply chain.

This paper proposes a multi methodology to support the preparedness decision on where to locate relief supply facilities to be used in the first 72 hours after a disaster strike. Based on humanitarian logistics literature reviews (Caunhye et al., 2012; Kunz \& Reiner, 2012; Leiras et al., 2014; Grass \& Fischer, 2016; Gutjahr \& Nolz, 2016), this paper marks the first time a multi-criteria, stochastic methodology has been applied for relief supply location problems. First, using a two-stage stochastic optimization model (Dantzig, 1955), sites are evaluated for installing distribution centers (depots), and the optimization process results in proposing locations that minimize the total operational cost of opening relief supply depots, considering opening costs and penalties for unmet demand. Then, as small differences in costs of the solutions may not be considered relevant enough by taking other criteria into account, these solutions are evaluated using Multi-criteria Decision Analysis (MCDA). The MCDA approach also covers qualitative, intangible (often contradictory) criteria not considered by traditional optimization models (Cheng et al., 2003).

Uncertainty is a characteristic of disasters and is introduced in the stochastic model by scenarios based on disaster severity (medium, large, and very large) that affect the demand for relief supplies. The media plays a key role in disasters, especially in mobilizing volunteers and donations, because media coverage influences people's perception of the urgency and makes them more willing to donate (Zagefka et al., 2011). Thus, this work also contributes to the discussion of purchases, donations, media disclosure, service level, and penalty calibration.

An application in Brazil illustrates the effectiveness of the proposed approach. Preparedness measures are necessary for public sector management (in this case, Sao Paulo State Civil Defense), including location and pre-positioning of relief supplies. The Sao Paulo state has a population of 44.749 .699 inhabitants (similar to Canada), area 248.221,996 km² (similar to United Kingdon) and Gross Domestic Product (GDP) 568.587 million USD (similar to Argentina) (Instituto Brasileiro de Geografia e Estatística, 2016).

\section{Theoretical foundation}

\subsection{Two-stage stochastic optimization models in humanitarian operations}

The application of stochastic optimization is indicated in disasters because there is uncertainty in the determination of the model components (Sen \& Higle, 1999). In two-stage models, the decision variables are cast into first and second stage variables. Decisions that must be made before uncertain events have unfolded are known as the first stage, while those implemented later are second-stage decisions. The decision variables of the first stage are often associated with planning issues and assigned to strategic decisions. Second-stage variables are generally related to tactical and operational decisions (Leiras et al., 2013; Ribas et al., 2012). In the second stage, the problem solution depends on the solution of the first stage; however, the first stage cannot be solved without understanding the behavior of the second-stage problem (Shapiro et al., 2009). A characteristic of stochastic models is the representation of uncertainty by scenarios. A scenario comprises each possible event for the problem, as well as the probability of occurrence of these events (Sen \& Higle, 1999).

Two-stage stochastic models have been widely used in humanitarian operations related problems - see Grass \& Fischer (2016) for a detailed literature review. In humanitarian logistics, stochastic optimization has been used to determine the location of warehouses for materials inventory, as well as assignment and distribution of resources for rescue. To account for uncertainty, a location problem can be formulated as a two-stage stochastic programming model, in which the first stage minimizes the distances, and the second stage performs the allocation of inventory (Chang et al., 2007). Mete \& Zabinsky (2010) evaluated the location of the medical supply warehouses and the inventory levels required for each medical source (first-stage decision) and delivery requirements for supplies through a second stage vehicle routing. Rawls \& Turnquist (2010) present a two-stage 
stochastic model for facility location considering, uncertainty in demand and penalty for unmet demand in various scenarios of disaster. Rawls \& Turnquist (2011) consider constraints of quality of service and an average distance of deposits up to demand nodes, and present an application in the United States. Later, Rawls \& Turnquist (2012) adapt the previous model for dynamic allocation (72 hours in advance) for short-term demands, which ensured meeting 100\% of customer service needs. Condeixa et al. (2017) incorporated risk management through the use of the conditional value at risk $(\mathrm{CVaR})$ in the two-stage stochastic model of pre-positioning, location, and distribution.

The penalties for unmet demand in the paper by Rawls \& Turnquist (2012) range from 10 to 50 times the value of the product. These values showed that for a given problem situation, the change in the value of penalties affects the number of deposits opened, as well as the total cost, indicating that the subjectivity of this value affects the problem solution. King \& Wallace (2012) state that it is up to the modeler to set penalty values and to recommend parametric analysis.

Noyan (2012) incorporate risk evaluation into Rawls \& Turnquist (2010, 2011, 2012) models, by introducing the concepts of the expected value of perfect information (EVPI) and the value of stochastic solution (VSS). Noyan (2012) highlights that the EVPI and the VSS are the two best-known performance measures for the stochastic solution. The EVPI could be understood as the maximal amount the decision-maker would be willing to pay for the exact information on future outcomes and is defined as the difference between the solution obtained by the decision-maker able to make the perfect prediction (wait-and-see - WS) and the solution obtained solving the problem under uncertainty (recourse problem - RP). The VSS could be interpreted as the benefit expected by taking uncertainty into account or as the loss expected by the decision-maker who opted for deterministic modeling using the average stochastic parameters. VSS is defined by the difference between the stochastic solution (RP), and the average solution of the EEV (expected value problem, fixing parameters to average values) (Birge \& Louveaux, 2011). The value of the penalty was established as ten times (in some cases, five times) the value of the product. The results showed the importance of risk allocation in locating humanitarian facilities.

Many recent studies on facility location, in terms of penalties, address deprivation costs in the objective function as a way of assuming the penalty of shortages over time (Balcik et al., 2016; Boonmee et al., 2017; Cotes \& Cantillo, 2019; Gutjahr \& Fischer, 2018; Wang et al., 2017). However, the results obtained from the functions defined in Holguín-Veras et al. (2016) and Pérez-Rodríguez \& Holguín-Veras (2016), considering 72 hours for supply show very different values reaching 3,528\%, when comparing these functions. Thus, Turkeš \& Sörensen (2019) and Balcik et al. (2016) suggest that it would be valuable to create benchmarks for humanitarian logistics problems.

Rawls \& Turnquist (2010, 2011, 2012); Noyan (2012); Mete \& Zabinsky (2010), and Bozorgi-Amiri et al. (2013) link penalties to the value of the product. In the present study, we adopt the approach of penalty of shortages over time and also link penalties to the value of product.

\subsection{MCDA in humanitarian operations}

The strategic decision of the location of permanent installations should consider multiple objectives that are often conflicting; interconnection of policies, long-term consequences resulting from the implementation of these decisions, and the engagement of stakeholders (Montibeller \& Franco, 2007). The three dimensions of MCDA (formal approach; the presence of several criteria; and decisions taken by individuals or groups) (Belton \& Stewart, 2002), similarly to studies on natural resource management (Mendoza \& Martins, 2006), are reasons why MCDA is an appropriate approach to deal with humanitarian location decisions, as it addresses several aspects, such as:

- Structured and rational approach capable of integrating key elements of humanitarian management;

- Existence of several criteria in humanitarian issues;

- Considers multiple stakeholders and interest groups, each with their own views, objectives, and requirements.

Regarding the criteria, in humanitarian logistics, cost minimization is not the focus during the response phase, but in the preparedness phase its importance increases. Whereas parameters such as response time, distribution equity, priority item reliability, and safety are more relevant during the distribution of relief supplies (Vitoriano et al., 2011), monetary and non-monetary aspects should be taken into account in post-disaster situations (Nolz et al., 2010). Carland et al. (2018) used quantitative measures for economic and non-economic objectives in the humanitarian and commercial supply chains to quantify the goals and priorities. 
Gutjahr \& Nolz (2016) review the literature on the application of multicriteria optimization to the management of natural disasters and humanitarian crises. They also divided the criteria in monetary and non-monetary and stated that the cost criterion could not be neglected. However, they present the following additional important criteria: response time, travel distance, coverage, reliability, security, equity, and distress (psychological or social costs).

Vitoriano et al. (2011) also postulate that time of response, equity of the distribution or reliability, and security of the operation routes are relevant performance measures in humanitarian operations.

\section{Problem statement}

We address the problem presented of establishing the local installation distribution centers for storing relief supplies to the victims of disasters that may occur in a region in the first 72 hours after the disaster onset. The modeling process focus on the preparedness phase (before the disaster onset) when Civil Defense agencies have budget restrictions and need to rationalize their facility networks (Bruno \& Genovese, 2016) optimizing costs in conjunction with service level criteria.

The two-stage stochastic optimization model minimizes the total operational cost of opening relief supply depots, considering capacity constraints (storage and transport); available materials constraints (inventory, donations, and purchases); and a minimum level of service (minimum fulfilled demand and coverage). The model results are where depots must be opened (optimal and suboptimal solutions), the inventory level that each depot should have, the number of materials to be purchased, the amount of material to be transported from the warehouse to the demand point and unmet demand. As decisions in humanitarian operations have more than one criterion, after the stochastic model, a multi-criteria method applied to this study. The approach adopted is the MAVT (Multi-Attribute Value Theory) (Keeney, 1992) and VFT (Value-Focused Thinking), which breaks down the fundamental objectives, using a facilitator in the process (Franco \& Montibeller, 2011).

The modelling is based on the two-stage stochastic models by Mete \& Zabinsky (2010) and Rawls \& Turnquist (2011). Mete \& Zabinsky (2010), however, applied their model to the location of medical supplies and consider vehicle routing in the second stage; whereas Rawls \& Turnquist (2011) present a stochastic facility location model considering various stochastic disaster scenarios and a penalty for unmet demand.

Products may be purchased by agreements previously negotiated (contracts) according to Brazilian public purchases law. When a disaster strikes, the supply to the victims is started from the relief supplies stored in the distribution centers and the materials received by purchase agreements previously negotiated. These purchases take place only if necessary (the demand is higher than the current inventory). The distribution center also has the function of processing donations to be sent to the disaster site.

From the warehouse, all relief supplies (previously stored, purchased, or received through donations) are sent to disaster sites to assist victims via road transport, with the possibility of discontinuity in the process of access to affected areas (ruptures in the transportation pathways). In the event of road disruptions, accessibility to the sites is compromised, making and increasing transportation costs.

In our stochastic modeling, scenarios were established according to the disaster severity and magnitude, the media disclosure, and disruption in access roads. The magnitude and severity of a disaster affect the demand for relief supplies, defining the needs of relief supplies, rescue teams, and logistics. Using definitions from the Brazilian Civil Defense (Brasil, 2007), disasters can be categorized into four levels:

- Level 1 - small-sized disasters. Small disasters were not considered in this paper because the community does not require relief supplies provided by the State Civil Defense;

- Level 11 - medium-sized disasters, the community itself exceeds the damages caused by the disaster, by external aid ( $5 \%<$ loss $<10 \%$ of the site GDP);

- Level 111 - large-sized disasters, when the local community needs to complement local resources with external assistance $(10 \%<$ loss $<30 \%$ of the site GDP);

- Level IV - very large disasters, when the effects of the disaster are of such magnitude that even prepared and mobilized communities do not outweigh the damages (loss> 30\% of the site GDP).

The media concept has two dimensions: space and time (Chyi \& McCombs, 2004). The space dimension can be divided into the individual, community, state/ regional, national, and international, according to the coverage level (Houston et al., 2012). In the case of ruptures in the transportation pathways, the scope was considered to be at least national. The international space was not considered, because the model is to serve 
the first 72 hours after the disaster and, in Brazil, there would not be enough time for international donations to reach the disaster site. Thus, the donation flow is assumed dependent on media coverage and the scenarios take this relationship into account.

Scenarios are summarized in Figure 1 (the number of the scenario is presented between brackets). The number of donations depends on the disaster level and the media coverage. Additionally, landslides and torrential rain sometimes isolate communities in Brazil, and attract larger media coverage; thus, rupture of road infrastructure must be considered in building the scenario.

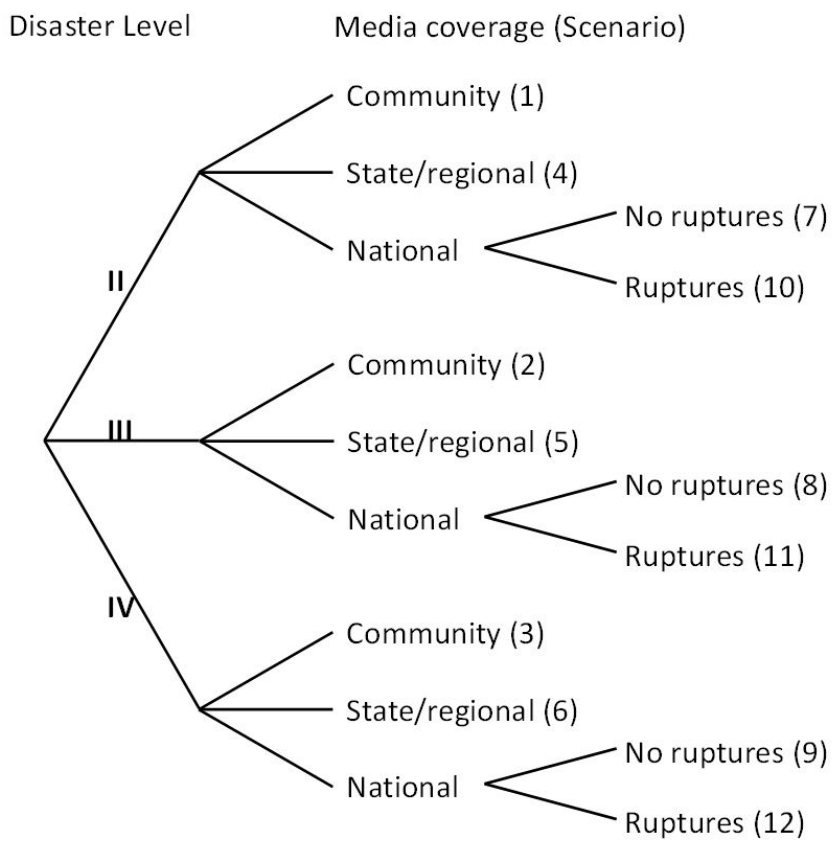

Figure 1. Disaster scenarios.

To MCDA interventions (Franco \& Montibeller, 2011), we consider an expert panel. The situation is first exposed, and the facilitator assists in defining the problem, designing the decision-making process and, together with the team of managers, defines the stakeholders. Once this phase is completed, the second phase starts, which consists in structuring a tree value, setting the attributes, and identifying the decision alternatives. During an MCDA intervention, attention to stakeholders is desired to assess and improve the political viability of decision implementation and important to convince and satisfy those involved or affected by the decision (Franco \& Montibeller, 2011).

\section{The stochastic model}

The model is based in Brito Junior et al. (2014). Sets, variables, and parameters are in Table 1. Then, the model is detailed.

\subsection{Nomenclature}

\subsubsection{Formulation}

$$
\min \sum_{\mathrm{i}} \mathrm{g}_{\mathrm{i}} \mathrm{X}_{\mathrm{i}}+\mathrm{E}_{\mathrm{C}}[\mathrm{Q}(\mathrm{X}, \mathrm{S}, \mathrm{c})]
$$

Subject to:

$$
\sum_{\mathrm{i}} \mathrm{S}_{\mathrm{ik}} \leq \mathrm{e}_{\mathrm{k}} \quad \forall \mathrm{k} \in \mathrm{K}
$$


Table 1 . Sets, variables, and parameters of the model.

\begin{tabular}{|c|c|}
\hline \multicolumn{2}{|r|}{ Index sets } \\
\hline 1 & Candidate distribution centers $(\mathrm{i} \in \mathrm{l}$ ) \\
\hline K & Relief supplies ( $\mathrm{k}$ K) \\
\hline $\mathrm{J}$ & Demand points $(\mathrm{j} \in \mathrm{J})$ \\
\hline C & Scenarios (c $\in \mathrm{C}$ ) \\
\hline \multicolumn{2}{|r|}{ Deterministic Parameters (unit) } \\
\hline$g_{i}$ & Annual cost of installation and operation of distribution center $i(\$)$ \\
\hline$e_{k}$ & Amount of supply $k(\mathrm{~kg})$ available \\
\hline $\mathrm{l}_{\mathrm{ik}}$ & Maximum regular storage capacity of $k$ in distribution center $i(\mathrm{~kg})$ \\
\hline $\mathrm{ne}_{\mathrm{ik}}$ & Minimum annual inventory of $k$ in distribution center $i(\mathrm{~kg})$ \\
\hline $\mathrm{qd}_{\max }$ & Maximum number of distribution centers to be opened \\
\hline$q d_{\min }$ & Minimum number of distribution centers to be opened \\
\hline$a_{i j}$ & $\begin{array}{l}\text { Binary that assumes the value of } 0 \text { if the distance is greater than the maximum distance and the value of } 1 \text { otherwise } \\
\text { (coverage matrix) }\end{array}$ \\
\hline $\mathrm{fv}_{\mathrm{k}}$ & Weight $\times$ volume conversion factor $\left(\mathrm{m}^{3} / \mathrm{kg}\right)$ \\
\hline M & Large auxiliary number, to make purchases of supplies $k$ only if necessary \\
\hline \multicolumn{2}{|r|}{ Scenario-dependent Parameters (unit) } \\
\hline $\mathrm{ct}_{\mathrm{ij}}^{\mathrm{c}}$ & Transportation cost from distribution center $i$ to demand point $j$ under scenario $c(\$ / \mathrm{kg})$ \\
\hline $\mathrm{w}_{\mathrm{jk}}^{\mathrm{c}}$ & Penalty per unit of $k$ not supplied to demand point $j$ under scenario $c(\$ / \mathrm{kg})$ \\
\hline $\mathrm{dn}_{\mathrm{ik}}^{\mathrm{c}}$ & Number of donations of $k$ received in distribution center $i$ under scenario $c(\mathrm{~kg})$ \\
\hline$d_{j k}^{c}$ & Demand of $k$ in demand point $j$ under scenario $c(\mathrm{~kg})$ \\
\hline $\mathrm{ac}_{\mathrm{i}}^{\mathrm{c}}$ & Binary parameter regarding the accessibility of distribution center $i(1$ - accessible, 0 not accessible) under scenario $c$ \\
\hline $\mathrm{cp}_{\mathrm{ij}}^{\mathrm{c}}$ & Transportation capacity by weight from distribution center $i$ to demand point $j$ under scenario $c(\mathrm{~kg})$ \\
\hline $\mathrm{cv}_{\mathrm{ij}}^{\mathrm{c}}$ & Transportation capacity by volume from distribution center $i$ to demand point $j$ under scenario $c\left(\mathrm{~m}^{3}\right)$ \\
\hline $\mathrm{dmin}_{\mathrm{jk}}^{\mathrm{c}}$ & Minimum demand of $k$ to be supplied at demand point $j$, under scenario $c(\mathrm{~kg})$ \\
\hline $\cot _{\mathrm{k}}^{\mathrm{c}}$ & Contractual limit established for purchases of $k$, under scenario $c(\mathrm{~kg})$ \\
\hline \multicolumn{2}{|r|}{ First-stage decision variables (unit) } \\
\hline$X_{i}$ & Binary equals 1 if a distribution center $i$ is opened, 0 otherwise \\
\hline$S_{i k}$ & Average inventory level of supply relief $k$ at distribution center $i(\mathrm{~kg})$ \\
\hline \multicolumn{2}{|r|}{ Second-stage decision variables (unit) } \\
\hline $\mathrm{T}_{\mathrm{ijk}}^{\mathrm{c}}$ & Amount of $k$ to transport from distribution center $i$ to point of demand $j$, under scenario $c(\mathrm{~kg})$ \\
\hline $\mathrm{F}_{\mathrm{jk}}^{\mathrm{c}}$ & The unmet demand of $k$, at point $j$ under scenario $c(\mathrm{~kg})$ \\
\hline $\mathrm{CO}_{\mathrm{ik}}^{\mathrm{c}}$ & Amount of $k$ purchased, allocated in distribution center $i$, under scenario $c(\mathrm{~kg})$ \\
\hline $\mathrm{CO}_{-} \mathrm{AUX}_{\mathrm{k}}^{\mathrm{c}}$ & Auxiliary binary variable to make purchases only if $k$ is necessary \\
\hline
\end{tabular}

$$
\begin{gathered}
\mathrm{l}_{\mathrm{ik}} \mathrm{X}_{\mathrm{i}} \geq \mathrm{S}_{\mathrm{ik}} \quad \forall \mathrm{i} \in \mathrm{I}, \mathrm{k} \in \mathrm{K} \\
\mathrm{ne}_{\mathrm{ik}} \mathrm{X}_{\mathrm{i}} \leq \mathrm{S}_{\mathrm{ik}} \quad \forall \mathrm{i} \in \mathrm{I}, \mathrm{k} \in \mathrm{K} \\
\sum_{\mathrm{i}} \mathrm{X}_{\mathrm{i}} \leq \mathrm{qd}_{\max } \quad \forall \mathrm{i} \in \mathrm{I} \\
\sum_{\mathrm{i}} \mathrm{X}_{\mathrm{i}} \geq \mathrm{qd}_{\min } \quad \forall \mathrm{i} \in \mathrm{I} \\
\sum_{\mathrm{i}} \mathrm{X}_{\mathrm{i}} \mathrm{a}_{\mathrm{ij}} \geq 1 \quad \forall \mathrm{j} \in \mathrm{J}
\end{gathered}
$$

The objective function (1) minimizes the operating cost of distribution centers plus the value of the solution of the second stage function. Constraint (2) establishes that, for an item $k$, the amount stored at every distribution 
center cannot exceed the maximum amount available. Constraint (3) limits the inventory level by the capacity of distribution center $i$, whereas Constraint (4) limits the minimum inventory of item $k$ to open a distribution center $i$. Constraints (5) and (6) limit the number of distribution centers to be opened, and (7) ensures the minimum distance from the point of demand to at least one distribution center i.

The second stage of the model is formulated as:

$$
\mathrm{Q}(\mathrm{X}, \mathrm{S}, \mathrm{c})=\min \sum_{\mathrm{i}} \sum_{\mathrm{j}}\left(\mathrm{ct}_{\mathrm{ij}}^{\mathrm{c}} \sum_{\mathrm{k}} \mathrm{T}_{\mathrm{ijk}}^{\mathrm{c}}\right)+\sum_{\mathrm{j}} \sum_{\mathrm{k}} \mathrm{w}_{\mathrm{jk}}^{\mathrm{c}} \mathrm{F}_{\mathrm{jk}}^{\mathrm{c}}
$$

Subject to:

$$
\begin{aligned}
& \sum_{\mathrm{j}}^{\mathrm{c}} \mathrm{T}_{\mathrm{ijk}}^{\mathrm{c}} \leq \mathrm{S}_{\mathrm{ik}}+\mathrm{dn}_{\mathrm{ik}}^{\mathrm{c}}+\mathrm{CO}_{\mathrm{ik}}^{\mathrm{c}} \quad \forall \mathrm{i} \in \mathrm{I}, \mathrm{k} \in \mathrm{K}, \mathrm{c} \in \mathrm{C} \\
& \mathrm{F}_{\mathrm{jk}}^{\mathrm{c}}=\mathrm{d}_{\mathrm{jk}}^{\mathrm{c}}-\sum_{\mathrm{i}} \mathrm{T}_{\mathrm{ijk}}^{\mathrm{c}} \mathrm{ac}_{\mathrm{i}}^{\mathrm{c}} \quad \forall \mathrm{j} \in \mathrm{J}, \mathrm{k} \in \mathrm{K}, \mathrm{c} \in \mathrm{C} \\
& \mathrm{l}_{\mathrm{ik}} \mathrm{X}_{\mathrm{i}} \geq \sum_{\mathrm{j}} \mathrm{T}_{\mathrm{j} j \mathrm{k}}^{\mathrm{c}} \mathrm{ac}_{\mathrm{i}}^{\mathrm{c}} \quad \forall \mathrm{i} \in \mathrm{I}, \mathrm{k} \in \mathrm{K}, \mathrm{c} \in \mathrm{C} \\
& \sum_{\mathrm{k}} \mathrm{T}_{\mathrm{ijk}}^{\mathrm{c}} \leq \mathrm{cp}_{\mathrm{ij}}^{\mathrm{c}} \quad \forall \mathrm{i} \in \mathrm{I}, \mathrm{j} \in \mathrm{J}, \mathrm{c} \in \mathrm{C} \\
& \sum_{\mathrm{k}} \mathrm{T}_{\mathrm{ijk}}^{\mathrm{c}} \mathrm{fv}_{\mathrm{k}} \leq \mathrm{cv}_{\mathrm{ij}}^{\mathrm{c}} \quad \forall \mathrm{i} \in \mathrm{I}, \mathrm{j} \in \mathrm{J}, \mathrm{c} \in \mathrm{C} \\
& \sum_{\mathrm{i}} \mathrm{T}_{\mathrm{ijk}}^{\mathrm{c}} \mathrm{ac}_{\mathrm{i}}^{\mathrm{c}} \geq \mathrm{dmin} \mathrm{jk}_{\mathrm{jk}}^{\mathrm{c}} \quad \forall \mathrm{j} \in \mathrm{J}, \mathrm{k} \in \mathrm{K}, \mathrm{c} \in \mathrm{C} \\
& \mathrm{M}\left(1-\mathrm{CO}_{-} \mathrm{AUX}_{\mathrm{k}}^{\mathrm{c}}\right)>\sum_{\mathrm{j}}^{\mathrm{d}_{\mathrm{jk}}^{\mathrm{c}}}-\sum_{\mathrm{i}} \mathrm{S}_{\mathrm{ik}}-\sum_{\mathrm{i}} \mathrm{dn}_{\mathrm{ik}}^{\mathrm{c}} \quad \forall \mathrm{k} \in \mathrm{K}, \mathrm{c} \in \mathrm{C} \\
& \mathrm{MCO}_{-} \mathrm{AUX}_{\mathrm{k}}^{\mathrm{c}} \geq \sum_{\mathrm{i}} \mathrm{S}_{\mathrm{ik}}+\sum_{\mathrm{i}} \mathrm{dn}_{\mathrm{ik}}^{\mathrm{c}}-\sum_{\mathrm{j}}^{\mathrm{c}} \mathrm{ck} \quad \forall \mathrm{k} \in \mathrm{K}, \mathrm{c} \in \mathrm{C} \\
& \mathrm{CO}_{\mathrm{ik}}^{\mathrm{c}} \leq \mathrm{M}\left(1-\mathrm{CO}_{-} \mathrm{AUX}_{\mathrm{k}}^{\mathrm{c}}\right) \quad \forall \mathrm{i} \in \mathrm{I}, \mathrm{k} \in \mathrm{K}, \mathrm{c} \in \mathrm{C} \\
& \cot _{\mathrm{k}}^{\mathrm{c}} \mathrm{x}_{\mathrm{i}} \geq \mathrm{CO}_{\mathrm{ik}}^{\mathrm{c}} \quad \forall \mathrm{i} \in \mathrm{I}, \mathrm{k} \in \mathrm{K}, \mathrm{c} \in \mathrm{C} \\
& \cot _{\mathrm{k}}^{\mathrm{c}} \geq \sum_{\mathrm{i}} \mathrm{CO}_{\mathrm{ik}}^{\mathrm{c}} \quad \forall \mathrm{k} \in \mathrm{K}, \mathrm{c} \in \mathrm{C} \\
& \sum_{\mathrm{i}} \mathrm{CO}_{\mathrm{ik}}^{\mathrm{c}} \leq \sum_{\mathrm{j}} \mathrm{d}_{\mathrm{jk}}^{\mathrm{c}}-\sum_{\mathrm{i}} \mathrm{S}_{\mathrm{ik}}-\sum_{\mathrm{i}} \mathrm{dn}_{\mathrm{ik}}^{\mathrm{c}}+\mathrm{CO}_{-} \mathrm{AUX}_{\mathrm{k}}^{\mathrm{c}} \mathrm{M} \quad \forall \mathrm{k} \in \mathrm{K}, \mathrm{c} \in \mathrm{C} \\
& \mathrm{S}_{\mathrm{ik}}, \mathrm{T}_{\mathrm{ijk}}^{\mathrm{c}}, \mathrm{F}_{\mathrm{jk}}^{\mathrm{c}}, \mathrm{CO}_{\mathrm{ik}}^{\mathrm{c}} \geq 0 \quad \forall \mathrm{i} \in \mathrm{I}, \mathrm{j} \in \mathrm{J}, \mathrm{k} \in \mathrm{K}, \mathrm{c} \in \mathrm{C} \\
& \mathrm{X}_{\mathrm{i}}, \mathrm{CO}_{-} \mathrm{AUX}_{\mathrm{k}}^{\mathrm{c}} \in\{0,1\} \quad \forall \mathrm{i} \in \mathrm{I}, \mathrm{k} \in \mathrm{K}, \mathrm{c} \in \mathrm{C}
\end{aligned}
$$

The objective function (8) minimizes the transportation cost under scenario c plus a penalty for unmet demand under scenario $c$. Constraint (9) ensures that relief supply $k$ to be transported from $i$ to demand point $j$ is available at $i$. Constraint (10) calculates the unmet demand for $k$ in $j$ under scenario $c$. Constraint (11) imply that relief supply $k$ being transported from $i$ to demand point $j$ is at the distribution center opened by $x_{i .}$. Constraints (12) and (13) are respectively used to limit the transport capacity by weight and volume of supply $k$. Constraint (14) ensures that a minimum demand of $k$ at demand point $j$ is met. Constraints (15) to (20) are employed for the purchase process: (15) establishes a condition for purchasing relief supplies $k$ if Demand - Inventory - Donations $>0\left(C O \_A U X=0\right)$ and (16) defines when no purchase is requested if Inventory + Donations - Demand >0 (CO_AUX = 1). Constraint 
(17) defines the purchase of relief supply $k$ only if CO_AUX $=0$. Constraint (18) imply that the purchase of supplies $k$ is allocated to the distribution center opened by $x_{\mathrm{i}}$. Constraint (19) ensures that the total purchase of supply $k$ allocated to each distribution center $i$ does not exceed the total contract al amount under scenario $c$, and (20) imply that the purchase of supplies $k$ is performed only after the consumption of the inventory and the donations received in $i$. Constraints (21) and (22) define non-negativity and binary variables, respectively.

\section{Case study}

The location model is applied to the case of the Paraiba Valley (São Paulo State-Brazil). The region, with two million inhabitants, is prone to natural disasters, both large ones resulting in over ten thousand displaced people and frequent minor disasters.

This study was used by Civil Defense to locate their depots. Five local candidates are considered: São Paulo, Caçapava, São José dos Campos, Taubaté, and Tremembé. These sites were chosen because they already house Civil Defense centers and have a history of few accidents, thus less likely to rupture.

The parameters were based on historical data about materials and transportation since 1999, available government budgets, risk maps, international guidelines, academic and field activities. The Sphere Project (2011) and United Nations High Commissioner for Refugees (2007) guidelines help in defining the demand of materials . They were classified into materials for individual use (e.g., clothes), for household use (average four persons per household - e.g., cleaning kits), and also materials for response teams (e.g., tools). Quantities for the population in need were considered in two dimensions: (1) Civil Defense historical data, and risk mapping conducted by municipalities that comprehend the number of households in a vulnerable situation, and (2) according to the magnitude of a disaster multiplied by a weighting value (Balcik \& Beamon, 2008). The quantities for the response teams were calculated based on the size and risk of the city.

Scenario probabilities were estimated based on an expert panel (Salmerón \& Apte, 2010), mostly civil defense officers. The probabilities were estimated using the Delphi method (Budnitz et al., 1998) to guarantee anonymity since there was a functional hierarchy among those specialists, which could influence opinions. They were hypothetically inquired upon natural disasters over the next five years and divided the percentages for the scenarios presented in Figure 1.

The questionnaire containing the disaster description and the scenarios were made available on a website (SurveyMonkey service). Experts from Civil Defense, Disasters, Geology, Meteorology, Architecture, and Journalism composed the panel. Nineteen questionnaires were sent to experts and nine answers were obtained, thus composing a quantity greater than the minimum recommended for the analysis (between 5 and 7) (García Valdés \& Suárez Marín, 2013; Rowe \& Wright, 2001).

Table 2 shows the scenario probabilities, defined on the average after conducting two rounds of consultations. Rowe $\&$ Wright (2001) recommend between 2-4 rounds. A hypothesis test with $\alpha=5 \%$ presented no differences between the means of the first and the second rounds. These probabilities are listed in Table 2 (the number of the corresponding scenario is presented between brackets).

Figure 2 illustrates the value tree. The weights of each attribute was established based on the swing-weights methodology (Montibeller et al., 2006). Initially, the costs, management and infrastructure criteria were assessed by stakeholders and, subsequently, the evaluation was conducted for each of the sub-criteria. For each criterion and sub-criterion, value functions were established according to the MCDA methodology (Franco \& Montibeller, 2011).

\subsection{Stochastic model}

The stochastic model was implemented using AIMMS 3.13, and CPLEX solver 12.6 in an Intel Core i7-4510U ${ }^{\circledR}$ $2.6 \mathrm{GHz}, 8 \mathrm{~Gb}$ RAM, 64-bit operational system Windows $10{ }^{\circledR}$ machine. The time to solve all the instances (RP, WS, deterministic, and EEV) was $29.49 \mathrm{~s}$.

Table 2. Probability of the scenarios.

\begin{tabular}{lccc}
\hline \multirow{2}{*}{ Media disclosure } & \multicolumn{3}{c}{ Disaster severity/magnitude } \\
\cline { 2 - 4 } & $\begin{array}{c}\text { Medium } \\
\text { (Level II) }\end{array}$ & $\begin{array}{c}\text { Large } \\
\text { (Level III) }\end{array}$ & $\begin{array}{c}\text { Very large } \\
\text { (Level IV) }\end{array}$ \\
\hline Community level & $24.00 \%(1)$ & $0.00 \%(2)$ & $0.00 \%(3)$ \\
State/regional level & $18.51 \%(4)$ & $8.11 \%(5)$ & $1.00 \%(6)$ \\
National level & $7.93 \%(7)$ & $15.33 \%(8)$ & $7.33 \%(9)$ \\
National level with access ruptures & $0.00 \%(10)$ & $13.56 \%(11)$ & $4.22 \%(12)$ \\
\hline
\end{tabular}




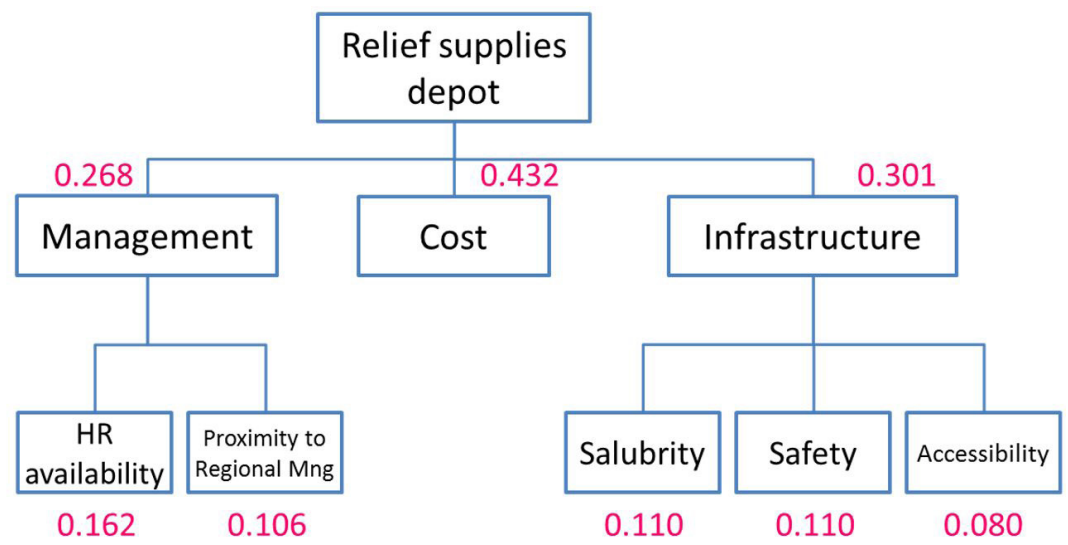

Figure 2. Value tree.

\subsubsection{Setting the penalties for the stochastic model}

Penalties for not meeting demand are established for the model calibration (Mete \& Zabinsky, 2010), verifying their impact on results. The choice of the penalty is determined by the decision-maker (Verma \& Gaukler, 2015). Unlike costs such as transportation, purchasing, and warehousing, there is no effective payment of the penalties, despite having a monetary unit, causing a characteristic of immateriality to the decision-maker. In this work, the main goal of calibration is to assure that shortages occur only due to model constraints, preventing viable non-supply, or producing unwanted results, as well as providing penalty values by other resulting costs.

Initially, the penalty was here set as the same for all products, and the transportation cost was chosen as the initial reference. The highest transportation cost between a candidate distribution center (i) and a demand point (j) was initially set as the lower limit because below this value, the model may allow shortages in the demand point as the cost of not supply is smaller than the transportation cost. The model behavior was evaluated from 1 to 10,000 times the highest transportation cost, similar to Barbarosoğlu \& Arda (2004). Figure 3 illustrates the behavior of total open deposits and the shortages due to penalties from 1 to 10 times the highest transportation cost (the behavior is the same for higher than 10 values).

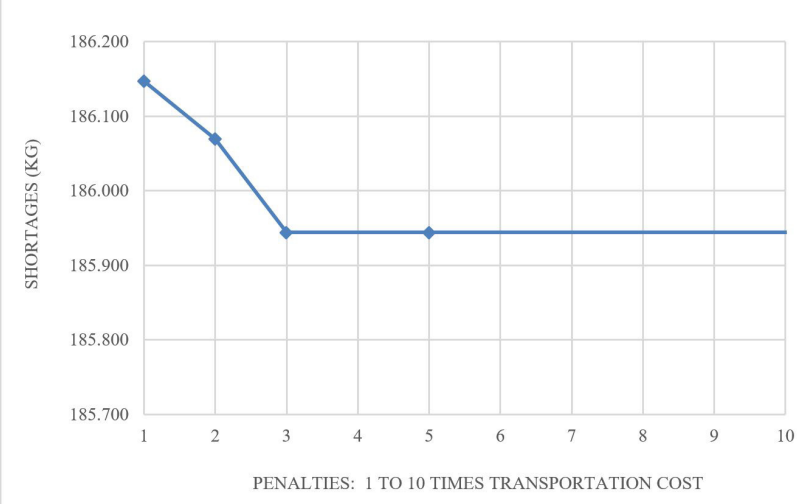

Figure 3. Shortages (sum of all the scenarios) according to penalties.

Note that even in the range of 1-3 times the highest transportation cost, the model allows shortages. Consequently, three times higher transportation cost was the lower limit set for penalties.

As shown in Figure 4, the EVPl, from 25 times the highest transportation cost, has an upward trend and then falls again because the WS solution for calculating the EVPI opens depots by scenarios. From penalty higher than 25 times the highest transportation cost, in some scenarios, depots are opened, increasing the difference in fixed costs between the solution obtained under uncertainty (recourse problem - RP) and the WS solution. This number of opened depots increases until the third depot is opened by a stochastic solution (RP). From 


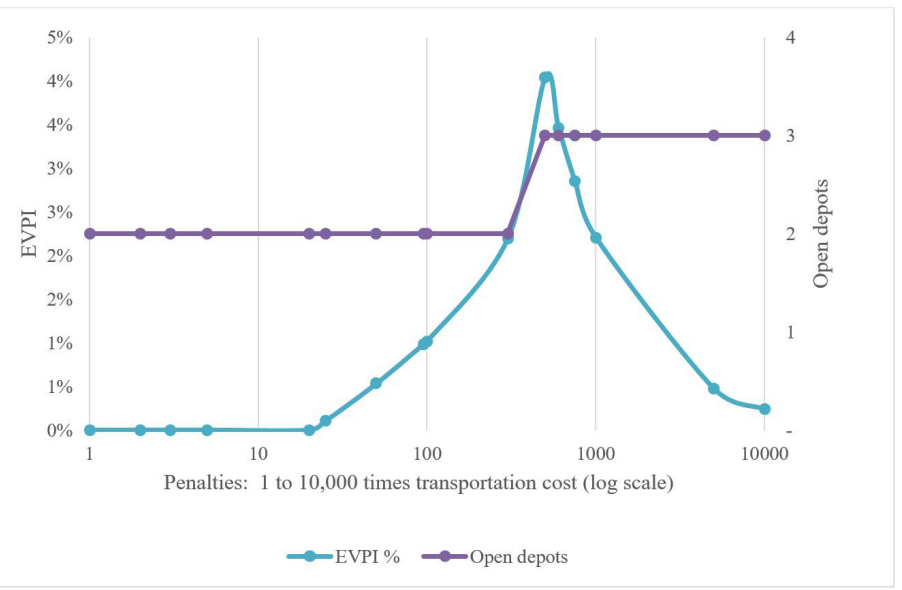

Figure 4. EVPl and open depots.

this point, the decline of the percentage value of EVPI (absolute value remains) is observed. Figure 4 shows the behavior of total open deposits (RP solution) and EVPI.

The penalty between 3 and 20 times the maximum value of the highest transportation cost can be assumed to produce similar results. For further analysis, we set this value at 20 .

\subsubsection{Stochastic model results}

The stochastic model results showed the optimal and suboptimal solutions for the cost criteria for 5 years. All the solutions present the city of São Paulo (SP), where there is already a depot and another city. The stochastic solution shows that the penalties (for 20 times the highest transportation cost) strongly influence the results due to the shortage of materials. Table 3 shows the results of stochastic models.

Table 3. Optimal and suboptimal stochastic solutions.

\begin{tabular}{ccc}
\hline Alternatives & Solutions & Cost (BRL\$) \\
\hline 1 & SP and Tremembé & $126,812.39$ \\
11 & SP and Taubaté & $126,844.24$ \\
111 & SP and Caçapava & $127,211.04$ \\
IV & SP and São José dos Campos & $127,733.52$ \\
V & SP, Taubaté and Tremembé & $185,223.29$ \\
\hline
\end{tabular}

The result for EVPI was $0.01 \%$ for penalties equal to 20 times the highest transportation cost. In the worst case, when the penalty is 500 times the highest transportation cost, EVPI was 4.03\%. Based on these values, good results are provided to EVPI in accommodation of the uncertainties. The behavior of VSS depends on and increases in function of the value of the penalties.

From the results, we analyze the shortages based on the transported relief supplies and demand for materials. Shortages occurred in all the scenarios due to unavailable materials or constraints. The materials were analyzed according to the user type (victims or rescue teams) because there were no donations of the items for the rescue teams. Table 4 shows the shortages according to the scenario.

Table 4. Shortages ( $\mathrm{kg}$ ) according to the scenario.

\begin{tabular}{cccc}
\hline \multirow{2}{*}{ Media disclosure } & \multicolumn{3}{c}{ Disaster severity/magnitude } \\
\cline { 2 - 4 } & Level II & Level III & Level IV \\
\hline Community & 252 & & 85,750 \\
State/regional & 237 & 1,047 & 48,217 \\
National & 201 & 1,011 & 48,217 \\
National and access ruptures & & 1,011 & \\
\hline
\end{tabular}


The findings show that for disasters of level 11 (all media disclosures), shortages appear only in relief supplies of the rescue teams due to an insufficient quantity of materials. In such cases, purchases were made up to the upper limit but were not sufficient to meet the demand.

In disasters of level IIl, shortages occurred not only due to the number of materials available but, in some cases, also with materials in sufficient quantity or able to be bought because constraints on storage capacity did not allow these materials to be used for assistance. In scenarios with regional/state media disclosure, the number of shortages was greater (4\%) than in the scenarios with national media disclosure.

In scenarios of disasters of level IV, the total shortage was greater than in disasters of level IIl, but the behavior was very similar. In scenarios with regional/state media disclosure (worst scenario) shortages occurred due to the number of materials available and constraints in storage capacity. In the scenarios with national media disclosure, the shortages also occurred due to unavailable materials and storage capacity, but shortages were reduced (by $47 \%$ in some cases), showing the media influence.

Changing the purchasing upper limit, the number of unavailable materials decreased. Regarding the storage capacity, we model these capacities for each deposit individually, as determined in the Brazilian Civil Defense plans. Using the idle capacity from another location if the capacity limit is reached, and establishing additional capacities were not considered. Disruptions only increased transportation costs because longer-distance alternative ways were available.

\subsection{MCDA model}

To define and elicit the criteria, a preliminary meeting with the manager's team decision, two meetings with all stakeholders, two meetings for final evaluation and a meeting for re-evaluation, also with the leadership team were performed ( 6 meetings, totaling approximately 10 hours). The authors acted as facilitators in these meetings. The technique used is the power-interest grid, which is shown in Figure 5.

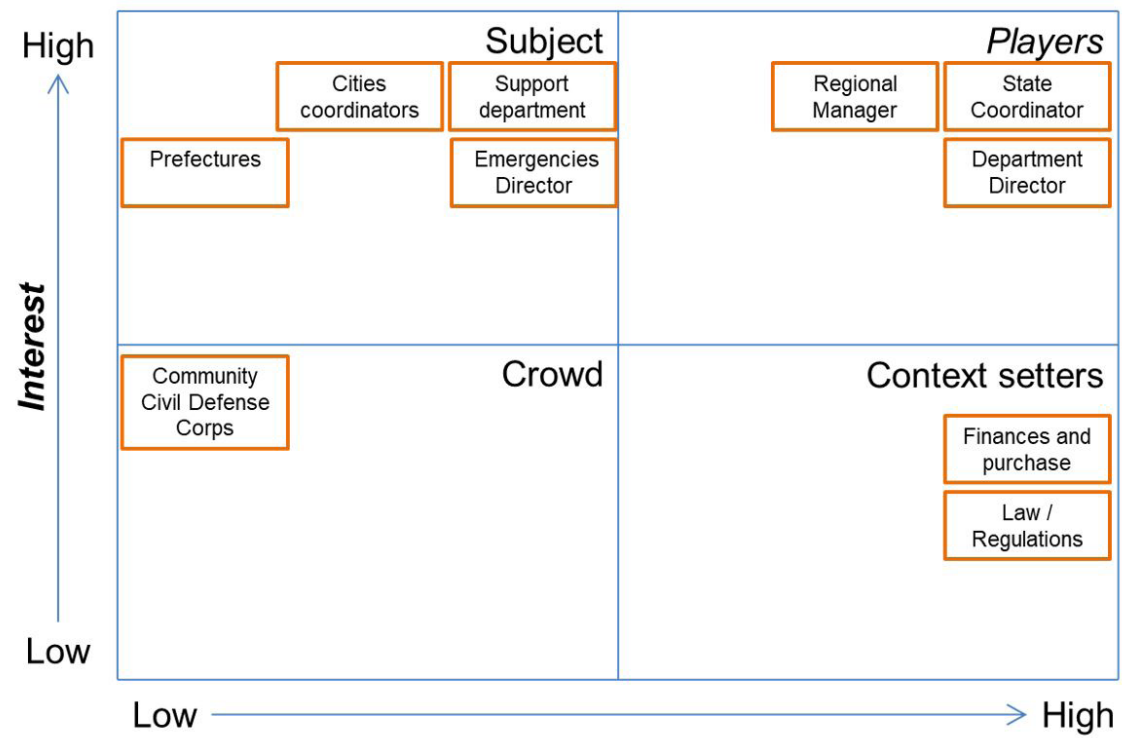

Figure 5. Power Interest Grid.

The value tree was defined using a top-down approach to decompose the primary goal into objectives and sub-objectives. Initially, using the brainstorming technique, the goals to be achieved when installing a new relief supply depot were discussed and mapped, as well as the values considered by stakeholders. After the mapping, standard features among the objectives were detected. These characteristics enabled the definition of sub-criteria and grouping the objectives for elaborating the tree value. The attributes were defined as follows:

- Cost: installing deposits for disaster preparedness is restrict to a budget. During the response phase, this objective changes, because minimizing human suffering (Holguín-Veras et al., 2013) is a priority activity about costs;

- Management, divided into two sub-objectives: 
$\checkmark$ Proximity to Civil Defense Regional Director: the Civil Defense Regional Director manages the relief supply distribution of a disaster operation, and the closer the depot is to the coordination, the better the operational readiness;

$\checkmark$ Human Resources: refers to labor mobilization during the disaster response operations.

- Infrastructure is divided into three objectives:

$\checkmark$ Safety: The social aspect refers to the site vulnerability to deviations or theft of materials; whereas the natural hazards aspects refer to the susceptibility to the occurrence of natural disasters and, consequently, unfeasible operations;

$\checkmark$ Hygiene and storage environment (salubrity): refers to the storage conditions and operational ease of storage, such as temperature, prevention of deterioration, and handling;

$\checkmark$ Accessibility: refers to the quality of routes to the depot; pavement conditions; lighting in the surroundings; signaling, and alternative routes that allow access in case of disruptions.

The management and salubrity criteria did not appear in our literature searches and are contributions of the expert panel to the academic literature.

According to the power interest grid, the experts evaluated the performance of the alternatives in each of the attributes and value from the function, the score on the corresponding criteria was obtained. Table 5 presents the evaluation results. The V.I.S.A. software allowed the stakeholders a direct visualization of their judgments.

Table 5. Results of stakeholder's evaluation of alternatives.

\begin{tabular}{cccccccc}
\hline $\begin{array}{c}\text { Solution: } \\
\text { SP depot + }\end{array}$ & $\begin{array}{c}\text { Proximity to Regional } \\
\text { Director }\end{array}$ & Human Resources & Cost (BRL\$) & Accessibility & Salubrity & Safety \\
\hline Caçapava & 20 & 75 & $126,812.39$ & 75 & 43 & 75 \\
Taubaté & 0 & 100 & $126,844.24$ & 100 & 79 & 75 \\
Tremembé & 15 & 50 & $127,211.04$ & 50 & 57 & 50 \\
São José dos Campos & 44 & 100 & $127,733.52$ & 100 & 79 & 100 \\
Taubaté + Tremembé (3 sites) & 0 & 100 & $185,223.29$ & 75 & 68 & 75 \\
\hline
\end{tabular}

The stochastic model provided the performance of local candidates concerning costs and coverage and showed that the best solution is two places and that the city of São Paulo is present in all solutions, because of the current operation and facilities already available, and consequently, fixed costs for allocation of relief supplies are only marginal. The cost difference between the optimal and three suboptimal points was lower than $0.8 \%$. The optimal solution and these three suboptimal solutions were selected for analysis, and a three places solution was added only for comparison. In summary, the stochastic solution alternatives to be evaluated are the ones already presented in Table 3.

The results after the application of the multi-criteria model are represented in Figure 6 and show the evaluation in each criterion and the final solution using the cities of São Paulo and Taubaté to be the best location for the relief supply depot.

After evaluating all the alternatives, the overall results were exposed to stakeholders for review. A survey form was used for results evaluation. The results were considered satisfactory, as well as the applicability to other regions in the State.

The sensitivity analysis was taken for the cost attribute in case of a change in the scaling constants, to evaluate whether or not discriminate solutions and also for the management attribute (sub-objective: Proximity to Civil Defense Regional Director) to assess if the change of the Regional Director modifies the results of the decision model.

Figure 7 shows the sensitivity analysis for variation in the scaling constants for the attribute Cost.

It can be observed that the range of variation does not affect the overall result of the model and that the alternative Taubate dominates the solution.

Figure 8 shows the sensitivity analysis for distance from the Civil Defense Regional Director (closer the depot is to the coordination, better is the operational readiness) in the results of attribute Management. 

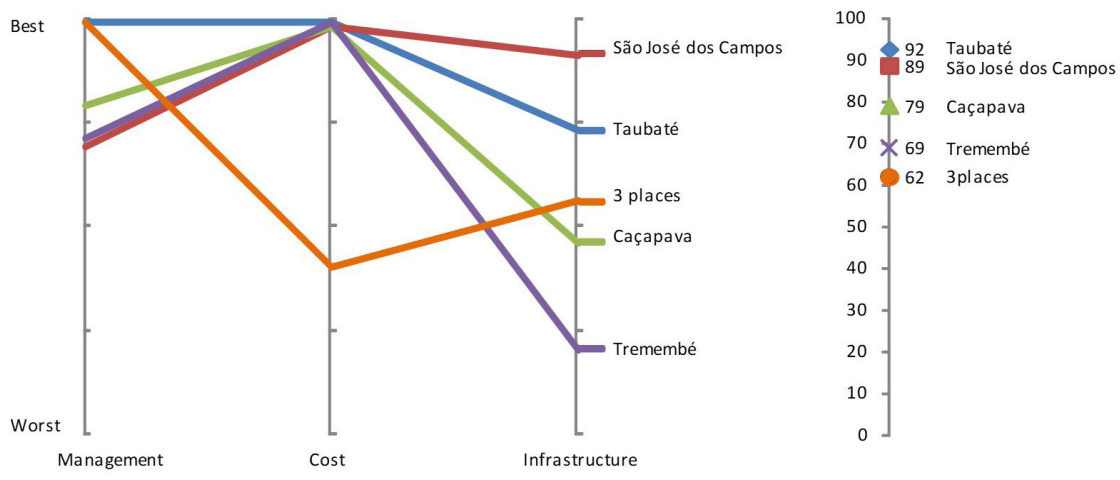

Figure 6. Criteria solutions and global performance.

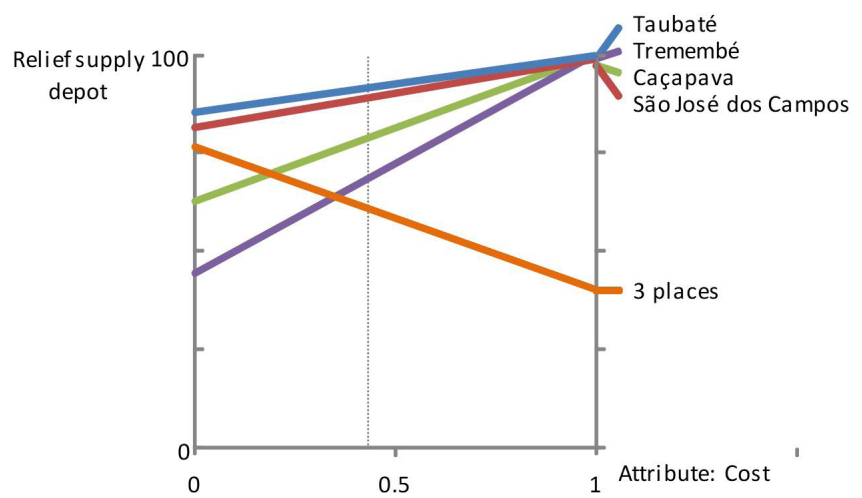

Figure 7. Sensitive analysis for the criteria Cost.

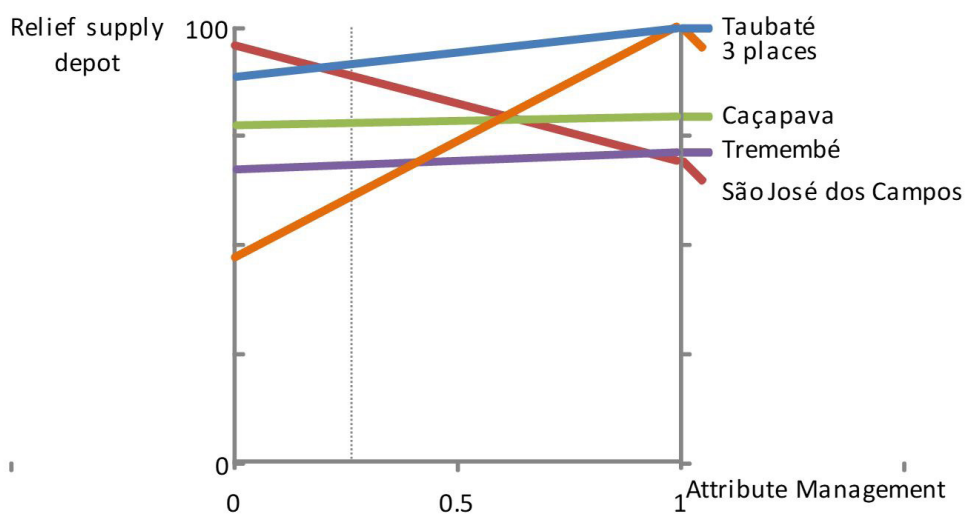

Figure 8. Sensitive analysis for the criteria Proximity to Regional Director.

It can be observed that the model is sensitive to the attribute Management (distance from Civil Defense Regional Director), which currently is located in the city of Taubaté. In case of a change in this attribute, the result can also be changed.

The results of multi-criteria modeling showed that characteristics concerning larger cities, located at road junctions, dominate the solutions. This finding occurs due to the management tools and infrastructure in these locations, especially larger units of the Military Police, which provide availability of human resources, in addition to better road accessibility. These locations provide better robustness to the solution because, in addition to characteristics of optimality, they count on Management and Infrastructure attributes, which ensure the operation under different scenarios. Sensitivity analyses showed that the result could be modified by changes in management attributes (distance from Civil Defense Regional Director). 


\section{Conclusions}

This paper presented a problem of pre-positioning disaster relief supplies through stochastic modeling and MCDA. Features of high impact in humanitarian operations - such as purchases, donations, media disclosure, disruptions to access routes, service level, and penalty calibration - were added to the stochastic model. The contribution is the sequential use of stochastic optimization and multiple criteria proposing a rational and systematic multi methodology for decision and easy and practical implementation.

Uncertainty scenarios were established based on disaster magnitude/ severity, media coverage, and ruptures in transportation pathways. The stochastic model performance was evaluated and presented good results for accommodating the uncertainties. Then, we assig penalties based on the behavior of the model through EVPl. This penalty calibration assures that the model behavior does not produce undesirable results and provides values following other costs.

The optimization results show that, in this Brazilian case, material availability for large disasters is an issue, and purchase budgets need to be increased for responding to disaster forecasts as the magnitude of the disaster increases, not only the materials availability but also the increase in storage capacity should be more effective. Media campaigns to improve donations may be useful to meet demand requirements.

The results of the stochastic model indicated the number of depots to be opened and the solutions based on transport, handling, and fixed costs as well as penalties for unmet demand. The model results also showed that the difference in costs between the optimal and suboptimal solutions was less than $0,8 \%$. These solutions were then evaluated by applying an MCDA for the decision-making process. The results show that intangible characteristics of the suboptimal solutions must be evaluated, since the qualitative aspects of these solutions may show better operational conditions than the optimal result. A comparison between the results of the stochastic model with the multi-criteria model highlights a change in location from Sao Paulo and Tremembe solutions to Sao Paulo and Taubaté. This pattern caused a displacement of $14 \mathrm{~km}$ in the solution.

The location model is applied to the case of the Paraiba Valley in São Paulo State - Brazil. Studies to extend the model to the entire state are in progress. The model can also be applied to other types of disasters or in different case studies. Input information, especially risk mapping used to estimate demand and historical supply data that may not be available, can be determined using other tools, such as regression models. Because the metholody involves decision-makers who participate during the modeling process and receive feedback from the effects of the decisions made, the model is well received by the Civil Defense personnel.

\section{Acknowledgments}

The authors would like to thank CAPES (BEX 7168/13-6, Pró-Alertas 88887.091739/2014-01 and 88887.091746/201401) and CNPQ (Universal 456711/2014-7, PQ 308084/2019-5 and DT-2 313687/2019-6)

\section{References}

Balcik, B., \& Beamon, B. M. (2008). Facility location in humanitarian relief. International Journal of Logistics: Research and Applications, 11(2), 101-121. http://dx.doi.org/10.1080/13675560701561789.

Balcik, B., Bozkir, C. D. C., \& Kundakcioglu, O. E. (2016). A literature review on inventory management in humanitarian supply chains. Surveys in Operations Research and Management Science, 21(2), 101-116. http://dx.doi.org/10.1016/j.sorms.2016.10.002.

Barbarosoğlu, G., \& Arda, Y. (2004). A two-stage stochastic programming framework for transportation planning in disaster response. The Journal of the Operational Research Society, 55(1), 43-53. http://dx.doi.org/10.1057/palgrave.jors.2601652.

Belton, V., \& Stewart, T. J. (2002). Multiple criteria decision analysis: an integrated approach (1st ed.). Norwell, Massachusetts: Kluwer Academic Publishers. http://dx.doi.org/10.1007/978-1-4615-1495-4.

Birge, J. R., \& Louveaux, F. (2011). Introduction to stochastic programming (2nd ed., Series in Operations Research and Financial Engineering). New York: Springer. http://dx.doi.org/10.1007/978-1-4614-0237-4

Blecken, A., Hellingrath, B., Dangelmaier, W., \& Schulz, S. F. (2009). A humanitarian supply chain process reference model. International Journal of Services Technology and Management, 12(4), 391. http://dx.doi.org/10.1504/1JSTM.2009.025815.

Boonmee, C., Arimura, M., \& Asada, T. (2017). Facility location optimization model for emergency humanitarian logistics. International Journal of Disaster Risk Reduction, 24, 485-498. http://dx.doi.org/10.1016/j.ijdrr.2017.01.017.

Bozorgi-Amiri, A., Jabalameli, M. S., \& Mirzapour Al-e-Hashem, S. M. J. (2013). A multi-objective robust stochastic programming model for disaster relief logistics under uncertainty. OR-Spektrum, 35(4), 905-933. http://dx.doi.org/10.1007/s00291-0B11-0268-x.

Brasil. (2007). Política Nacional de Defesa Civil. Brasília: Ministério da Integração Nacional, Secretaria Nacional de Defesa Civil.

Brito Junior, 1., Leiras, A., \& Yoshizaki, H. T. Y. (2014, May 9-12). Pre-positioning relief supplies in Brazil through location decisions. In. Proceedings of POMS 25th Annual Conference. Atlanta, USA: POMS - Production and Operations Management Society. http:// www.pomsmeetings.org/EventsNet/evNet/evNetSessBrowse/BrowseAbs.aspx?pr=1\&ev=51 
Bruno, G., \& Genovese, A. (2016). Location analysis for public sector decision-making in uncertain times: an introduction to the special issue. Socio-Economic Planning Sciences, 53, 2-3. http://dx.doi.org/10.1016/j.seps.2016.02.002.

Budnitz, R. J., Apostolakis, G., Boore, D. M., Cluff, L. S., Coppersmith, K. J., Cornell, C. A., \& Morris, P. A. (1998). Use of technical expert panels: applications to probabilistic seismic hazard analysis. Risk Analysis, 18(4), 463-469. http://dx.doi.org/10.1111/j.1539-6924.1998. tb00361.x.

Caunhye, A. M., Nie, X., \& Pokharel, S. (2012). Optimization models in emergency logistics: a literature review. Socio-Economic Planning Sciences, 46(1), 4-13. http://dx.doi.org/10.1016/j.seps.2011.04.004.

Carland, C., Goentzel, J., \& Montibeller, G. (2018). Modeling the values of private sector agents in multi-echelon humanitarian supply chains. European Journal of Operational Research, 269(2), 532-543. http://dx.doi.org/10.1016/J.EJOR.2018.02.010.

Chang, M.-S., Tseng, Y.-L., \& Chen, J.-W. (2007). A scenario planning approach for the flood emergency logistics preparation problem under uncertainty. Transportation Research Part E, Logistics and Transportation Review, 43(6), 737-754. http://dx.doi.org/10.1016/j. tre.2006.10.013.

Cheng, S., Chan, C. W., \& Huang, G. H. (2003). An integrated multi-criteria decision analysis and inexact mixed integer linear programming approach for solid waste management. Engineering Applications of Artificial Intelligence, 16(5-6), 543-554. http:// dx.doi.org/10.1016/S0952-1976(03)00069-1.

Chyi, H. 1., \& McCombs, M. (2004). Media salience and the process of framing: coverage of the Columbine school shootings. Journalism \& Mass Communication Quarterly, 81(1), 22-35. http://dx.doi.org/10.1177/107769900408100103.

Condeixa, L. D., Leiras, A., Oliveira, F., \& de Brito Junior, 1. (2017). Disaster relief supply pre-positioning optimization: A risk analysis via shortage mitigation. International Journal of Disaster Risk Reduction, 25(September), 238-247. http://dx.doi.org/10.1016/j. ijdrr.2017.09.007.

Cotes, N., \& Cantillo, V. (2019). Including deprivation costs in facility location models for humanitarian relief logistics. Socio-Economic Planning Sciences, 65, 89-100. http://dx.doi.org/10.1016/j.seps.2018.03.002.

Dantzig, G. B. (1955). Linear programming under uncertainty. Management Science, 1(3-4), 197-206. http://dx.doi.org/10.1287/ mnsc.1.3-4.197.

Franco, L. A., \& Montibeller, G. (2011). Problem structuring for multicriteria decision analysis interventions. In J. J. Cochran (Ed.), Wiley Encyclopedia of operations research and management science. Hoboken: John Wiley \& Sons. http://dx.doi.org/10.1002/9780470400531. eorms0683

García Valdés, M., \& Suárez Marín, M. (2013). El método Delphi para la consulta a expertos en la investigación científica. Revista Cubana de Salud Pública, 39(2), 253-267. Retrieved October 20, 2016, from http://bvs.sld.cu/revistas/spu/vol39_2_13/spu07213.htm

Grass, E., \& Fischer, K. (2016). Two-stage stochastic programming in disaster management: a literature survey. Surveys in Operations Research and Management Science, 21(2), 85-100. http://dx.doi.org/10.1016/j.sorms.2016.11.002.

Gutjahr, W. J., \& Fischer, S. (2018). Equity and deprivation costs in humanitarian logistics. European Journal of Operational Research, 270(1), 185-197. http://dx.doi.org/10.1016/j.ejor.2018.03.019.

Gutjahr, W. J., \& Nolz, P. C. (2016). Multicriteria optimization in humanitarian aid. European Journal of Operational Research, 252(2), 351-366. http://dx.doi.org/10.1016/j.ejor.2015.12.035.

Holguín-Veras, J., Amaya-Leal, J., Cantillo, V., Van Wassenhove, L. N., Aros-Vera, F., \& Jaller, M. (2016). Econometric estimation of deprivation cost functions: a contingent valuation experiment. Journal of Operations Management, 45(1), 44-56. http://dx.doi. org/10.1016/j.jom.2016.05.008.

Holguín-Veras, J., Pérez, N., Jaller, M., Van Wassenhove, L. N., \& Aros-Vera, F. (2013). On the appropriate objective function for post-disaster humanitarian logistics models. Journal of Operations Management, 31(5), 262-280. http://dx.doi.org/10.1016/j.jom.2013.06.002.

Houston, J. B., Pfefferbaum, B., \& Rosenholtz, C. E. (2012). Disaster news: framing and frame changing in coverage of major U.S. natural disasters, 2000-2010. Journalism \& Mass Communication Quarterly, 89(4), 606-623. http://dx.doi.org/10.1177/1077699012456022.

Instituto Brasileiro de Geografia e Estatística - IBGE. (2016). Síntese de indicadores 2015. Retrieved October 20, 2016, from http:// www.ibge.gov.br/home/estatistica/populacao/trabalhoerendimento/pnad2015/sintese_defaultxls.shtm

Jeworrek, T. (2017). Natural disasters in 2017 were a sign of things to come: new coverage concepts are needed. Munich: Munich RE. Retrieved October 20, 2016, from https://www.munichre.com/topics-online/en/climate-change-and-natural-disasters/naturaldisasters/natural-disasters-2017.html

Keeney, R. L. (1992). Value-focused thinking: a path to creative decision-making. Cambridge: Harvard University Press.

Kessler, M. (2013). Logistics network design in Africa. Berne: Haupt Verlag.

King, A. J., \& Wallace, S. W. (2012). Modeling with Stochastic Programming (pp. 33-60). New York: Springer. http://dx.doi.org/10.1007/9780-387-87817-1_2

Kunz, N., \& Reiner, G. (2012). A meta-analysis of Humanitarian Logistics research. Journal of Humanitarian Logistics and Supply Chain Management, 2(2), 116-147. http://dx.doi.org/10.1108/20426741211260723.

Leiras, A., Brito Junior, l., Peres, E. Q., Bertazzo, T. R., \& Yoshizaki, H. T. Y. (2014). Literature review of humanitarian logistics research: trends and challenges. Journal of Humanitarian Logistics and Supply Chain Management, 4(1), 95-130. http://dx.doi.org/10.1108/ JHLSCM-04-2012-0008.

Leiras, A., Ribas, G., Hamacher, S., \& Elkamel, A. (2013). Tactical and operational planning of multirefinery networks under uncertainty: an iterative integration approach. Industrial \& Engineering Chemistry Research, 52(25), 8507-8517. http://dx.doi.org/10.1021/ie302835n.

Mendoza, G. A., \& Martins, H. (2006). Multi-criteria decision analysis in natural resource management: a critical review of methods and new modelling paradigms. Forest Ecology and Management, 230(1-3), 1-22. http://dx.doi.org/10.1016/j.foreco.2006.03.023.

Mete, H. 0., \& Zabinsky, Z. B. (2010). Stochastic optimization of medical supply location and distribution in disaster management. International Journal of Production Economics, 126(1), 76-84. http://dx.doi.org/10.1016/j.jpe.2009.10.004.

Montibeller, G., \& Franco, L. A. (2007). Decision and risk analysis for the evaluation of strategic options. In F. A. O'Brien \& R. G. Dyson (Eds.), Supporting strategy: frameworks, methods and models (pp. 251-284). Chichester: Wiley. 
Montibeller, G., Gummer, H., \& Tumidei, D. (2006). Combining scenario planning and multi-criteria decision analysis in practice. Journal of Multi-Criteria Decision Analysis, 14(1-3), 5-20. http://dx.doi.org/10.1002/mcda.403.

Nolz, P. C., Doerner, K. F., \& Hartl, R. F. (2010). Water distribution in disaster relief. International Journal of Physical Distribution \& Logistics Management, 40(8/9), 693-708. http://dx.doi.org/10.1108/09600031011079337.

Noyan, N. (2012). Risk-averse two-stage stochastic programming with an application to disaster management. Computers \& Operations Research, 39(3), 541-559. http://dx.doi.org/10.1016/j.cor.2011.03.017.

Pérez-Rodríguez, N., \& Holguín-Veras, J. (2016). Inventory-allocation distribution models for postdisaster humanitarian logistics with explicit consideration of deprivation costs. Transportation Science, 50(4), 1261-1285. http://dx.doi.org/10.1287/trsc.2014.0565.

Rawls, C. G., \& Turnquist, M. A. (2010). Pre-positioning of emergency supplies for disaster response. Transportation Research Part B: Methodological, 44(4), 521-534. http://dx.doi.org/10.1016/j.trb.2009.08.003.

Rawls, C. G., \& Turnquist, M. A. (2011). Pre-positioning planning for emergency response with service quality constraints. OR-Spektrum, 33(3), 481-498. http://dx.doi.org/10.1007/s00291-011-0248-1.

Rawls, C. G., \& Turnquist, M. A. (2012). Pre-positioning and dynamic delivery planning for short-term response following a natural disaster. Socio-Economic Planning Sciences, 46(1), 46-54. http://dx.doi.org/10.1016/j.seps.2011.10.002.

Ribas, G. P., Leiras, A., \& Hamacher, S. (2012). Operational planning of oil refineries under uncertainty. IMA Journal of Management Mathematics, 23(4), 397-412. http://dx.doi.org/10.1093/imaman/dps005.

Rowe, G., \& Wright, G. (2001). Expert opinions in forecasting: the role of the Delphi technique. In J. S. Armstrong (Ed.), Principles of forecasting: a handbook for researchers and practitioners (pp. 125-144). Dordrecht: Kluwer Academic Publishers. http://dx.doi. org/10.1007/978-0-306-47630-3_7.

Salmerón, J., \& Apte, A. (2010). Stochastic optimization for natural disaster asset prepositioning. Production and Operations Management, 19(5), 561-574. http://dx.doi.org/10.1111/j.1937-5956.2009.01119.x.

Sen, S., \& Higle, J. L. (1999). An introductory tutorial on stochastic linear programming models. Interfaces, 29(2), 33-61. http://dx.doi. org/10.1287/inte.29.2.33.

Shapiro, A., Dentcheva, D., \& Ruszczynski, A. (2009). Lectures on stochastic programming: modeling and theory. Philadelphia: SIAM. http://dx.doi.org/10.1137/1.9780898718751.

The Sphere Project (2011). The Sphere Project humanitarian charter and minimum standards in humanitarian response (3rd ed., Vol. 1). Rugby, UK: Practical Action Publishing. Retrieved October 20, 2016, from www.practicalactionpublishing.org/sphere

Tomasini, R., \& Van Wassenhove, L. N. (2009). Humanitarian logistics (1st ed.). London: Palgrave Macmillan. http://dx.doi. $\operatorname{org} / 10.1057 / 9780230233485$.

Turkeš, R., \& Sörensen, K. (2019). Instances for the problem of pre-positioning emergency supplies. Journal of Humanitarian Logistics and Supply Chain Management, 9(2), 172-195. https://doi.org/10.1108/JHLSCM-02-2018-0016.

United Nations High Commissioner for Refugees - UNHCR. (2007). Handbook for emergencies (3rd ed.). Geneva: UNHCR.

Verma, A., \& Gaukler, G. M. (2015). Pre-positioning disaster response facilities at safe locations: an evaluation of deterministic and stochastic modeling approaches. Computers \& Operations Research, 62, 197-209. http://dx.doi.org/10.1016/j.cor.2014.10.006.

Vitoriano, B., Ortuño, M. T., Tirado, G., \& Montero, J. (2011). A multi-criteria optimization model for humanitarian aid distribution. Journal of Global Optimization, 51(2), 189-208. http://dx.doi.org/10.1007/s10898-010-9603-z.

Wallemacq, P., \& House, R. (2018). Economic losses, poverty \& disasters 1998-2017. Geneva: UNISDR. Retrieved October 20, 2016, from https://www.unisdr.org/files/61119_credeconomiclosses.pdf

Wang, X., Wang, X., Liang, L., Yue, X., \& Van Wassenhove, L. N. (2017). Estimation of deprivation level functions using a numerical rating scale. Production and Operations Management, 26(11), 2137-2150. http://dx.doi.org/10.1111/poms.12760.

Zagefka, H., Noor, M., Brown, R., de Moura, G. R., \& Hopthrow, T. (2011). Donating to disaster victims : Responses to natural and humanly caused events. European Journal of Social Psychology, 41(3), 353-363. http://dx.doi.org/10.1002/ejsp.781. 